IRA-International Journal of Education \& Multidisciplinary Studies

ISSN 2455-2526; Vol.04, Issue 01 (2016)

Institute of Research Advances

http://research-advances.org/index.php/IJEMS

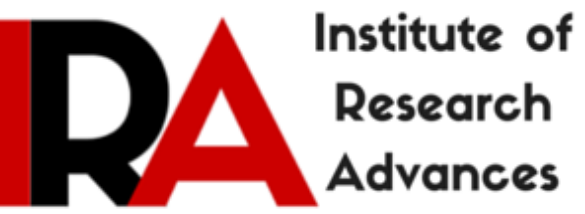

\title{
Vowel Harmony in Kui
}

\author{
Dr. Govinda Chandra Penthoi \\ Guest Faculty, Dept. of Linguistics \\ Berhampur University \\ Bhanjabihar- 760007, India.
}

DOI: http://dx.doi.org/10.21013/jems.v4.n1.p21

\section{How to cite this paper:}

Penthoi, G. (2016). Vowel Harmony in Kui. IRA International Journal of Education and Multidisciplinary Studies (ISSN 2455-2526), 4(1).

doi:http://dx.doi.org/10.21013/jems.v4.n1.p21

(C) Institute of Research Advances

(oc) EY-NC

This works is licensed under a Creative Commons Attribution-Non Commercial 4.0 International License subject to proper citation to the publication source of the work.

Disclaimer: The scholarly papers as reviewed and published by the Institute of Research Advances (IRA) are the views and opinions of their respective authors and are not the views or opinions of the IRA. The IRA disclaims of any harm or loss caused due to the published content to any party. 


\begin{abstract}
Kui (ISO639-3 Code 'Kxu') is a language spoken by Kondh or Kondha (/Kondho/) tribe. Majority of the Kui-speaking Kondhs live in the hilly and forested areas of South and central Odisha especially in the undivided districts of Kondhamal, Koraput and Kalahandi. The other language spoken by Kondhs is Kuvi which is very similar to Kui. Kondh people being an underdeveloped tribal people, study of their language, society and culture draws a lot of attention of academics, administration and other philanthropic agencies.

The objective of this study is to present the vowel sound harmony and phonology of Kui language. The approach is data oriented and uses in general. The structuralist methodology has been followed for the analysis of the data in the present work. Data was collected from the native speakers through field visit to various Kui speaking areas.
\end{abstract}

Keywords - 'Kui, Vowel, Central Dravidian, Non-nasalized, Nasalized. Segmental Sound

\title{
Introduction
}

Thee are four major language families in India i.e., Indo-Aryan, Dravidian, Tibeto-Burman and Austro-Asiatic, Kui is the language of the Kond (Khond or Kondh) people. According to W.W. Winfield, B.A., B.D. (A vocabulary of the Kui language, 1929, Page No.VIII) the Kond people live mainly in the mountainous country that lays between the river Mahanadi in Orissa and the north-west corner of Vizagapatam district in Madras. It is one of the languages belonging to the Dravidian group.

Contact with other people is increasing, and intellectual understanding is advancing with education. Thus the Konds are in need for fresh terms and phrases to express their widening experiences. It should be pointed out here that the Odia language, which is the major language of the state is surrounding the Kond country on three sides. It is also the main linguistic medium in educational, social and religious spheres. Kui therefore, is borrowing words and other linguistic features from Odia. In some districts a large number of Odia words have intermingled in the ordinary speech of the Konds and in other parts the proportion is less. This fluctuation is due to the amount of contact the Hillman have with the Odia people. But generally speaking Odia influence is more marked in the north and north-east of the Kond country than that in the South.

Kui has no script. So it is quite natural that it does not have any written literature. Though contain translations of the Bible and a few school books have been produced in recent years by missionaries and certain interested bodies, they have been written in the Odia script. The Konds are scattered in so many different districts like Ganjam, Boudh-Kondhamal, Koraput, Kalahandi, Nayagarh and Balasore. A clear difference of vocabulary and pronunciation in various localities can be noticed as one travels through the Kandhamal in the north to Ghumusar and Udayagiri Taluka in the east and then westward to the Baliguda Taluka. Though a large number of words are commonly used in all parts of areas among the Kond people. Principally there are two dialects such as (i) the eastern dialect spoken in Ghumusar and the neighboring areas and (ii) the southern dialect spoken in Ganjam, Koraput, Kalahandi, Kondhamal and Boudh. But according to Grierson (Linguistic survey of India vol. 2, Calcutta) Northern Kui speakers have come under the influence of neighboring IndoAryan speakers.

Long ago Rev. F.V.P. Schulz published two books i.e., Kuvi Grammar (Madras 1911) and vocabulary of the Kuvi-Kond language (Madras 1913) for establishing the Kui language.

But he failed because at that time as he did not know the language. Therefore both the books contained data which were a mixture of Kui and the Salur language that in spoken in Koraput (Gopinath Mohanty), Kuvi Kondh Bhasa Tattwo June, 1956, Page 2).

For this Schulz wrote in the Koraput district Gazette $(1945,57-58)$ that the Kuvi language of the Ganjam agency and of the Kandhamal has been clearly studied and there are grammars of the 
language along with small literatures. There are however been practically no research on the language as spoken in the Kondhamal and in the Ganjam district. The only publications are a grammar and a vocabulary which deal with the language of the Konds of the eastern slopes of the Pattangi Taluka (Koraput district). These are also strongly influenced by Telugu.

Some scholars have discovered that there are close affinities between Kui and Telugu. Besides Kuvi, Kond and Telugu it has close relationship with the other central Dravidian language like Gondi, Kolami, Naiki, Ollari, Gadba, Parji, Pengo and Manda etc.

The number of Kui speakers and its percentage of total population of Orissa and the position among the languages of the state according to the year 1961, 1971, 1981, 1991 and 2001 census are given bellow:

\begin{tabular}{|l|c|c|l|l|l|}
\hline Year & $\mathbf{1 9 6 1}$ & $\mathbf{1 9 7 1}$ & $\mathbf{1 9 8 1}$ & $\mathbf{1 9 9 1}$ & $\mathbf{2 0 0 1}$ \\
\hline No. of speakers & $5,12,161$ & $3,50,303$ & $5,07,528$ & 641662 & 916222 \\
\hline \% of total population of Orissa & $2.91 \%$ & $1.60 \%$ & $1.94 \%$ & $2.02 \%$ & $2.5 \%$ \\
\hline Position among languages & Second & Fourth & Fifth & NA & Third \\
\hline
\end{tabular}

Persons who returned the language as their mother tongue and its decadal percentage increase of the state according to the 1971, 1981, 1991 and 2001 census are as follows:

\begin{tabular}{|l|l|l|l|l|l|l|l|}
\hline \multirow{2}{*}{ Language } & \multicolumn{3}{|c|}{$\begin{array}{l}\text { Persons who returned the language as their mother } \\
\text { tongue }\end{array}$} & \multicolumn{3}{c|}{ Decadal percentage growth } \\
\cline { 2 - 8 } & 1971 & 1981 & 1991 & 2001 & $1971-81$ & $1981-91$ & $1991-2001$ \\
\hline Kui & 351,017 & 521,585 & 641,662 & 916,222 & $48.59 \%$ & $23.02 \%$ & $42.79 \%$ \\
\hline Odia & $19,863,198$ & $23,021,528$ & $28,061,313$ & $33,017,446$ & $15.90 \%$ & $21.89 \%$ & $17.66 \%$ \\
\hline
\end{tabular}

\section{Objectives}

Vowel-harmony is a common characteristic of many Dravidian languages, Kui is a Dravidian language. The scope of the present work is to study Vowel-harmony in Kui.

\section{Methodology}

The data is collected from an informant named Mr. Keshab Mallick (46 years) who is a native speaker of Kondhamal dialect of Kui. He is the resident of Retudi (Po-Kuminga Via-Kalinga) of Kondhamal district and is a matriculate. He knows Odia, Hindi and also English to some extent. The study is based on structuralist model (Lyons, 1968)

\section{Vowel-Harmony}

Vowel harmony is a process in which the vowels of two successive syllables in a word become similar in certain ways. It roughly means that the vowels must agree in being either front or back. Both front and back vowels cannot occur in the same word, rather vowels occurring in two syllables share some common qualities in a word. In other words the relation between them is one of degree of openness or closeness of articulation. In other words this is coupled with lip rounding or lack of lip rounding for both the syllables. To put it differently vowel-harmony is a set of vowel assimilation in which one vowel influences another and makes it more similar. There are two types of assimilation: 1. Progressive, in which the assimilated sound follows the assimilating are 2. Regressive, in which the assimilated sound precedes the assimilating sound. Assimilation may be conditioned by an immediately adjacent sound that is called contiguous in contract to non-contiguous sounds. According to Gleason (1868:84) is commonest type of non-contiguous assimilation is vowelharmony. So far the study of vowel harmony has remained confined largely to the word level.

There are a number of languages spoken in different areas of the world i.e., Efix, Twi and Igbo in Africa and Telugu, Bengali, Kui and Soura etc. in India. If we look at different languages we 
will find different pattern of vowel-harmony. Let us take the example of Igbo. According to J. Carnochon (Phonology, Erik C. Fudge p.200) there is a eight vowel system in Igbo. The vowels are / $\mathrm{I}, \mathrm{e}, \varepsilon, \mathrm{a}, \mathrm{\rho}, \mathrm{o}, \theta, \mathrm{u})$. It is a fact that vowel-harmony is found in some words or grammatical structures and not in others in this language. Vowel harmony in Igbo is a method of considering the relation between vowel qualities in successive syllables in words spoken in isolation or in certain selected grammatical constructions.

In this language the vowel sound in the second syllable of each example is the same as that in the final syllable and they together constitute one utterance. These are not two separate independent utterances. For example:

$\begin{array}{ll}\text { m siri } & \text { I cooked } \\ \text { m sara } & \text { I quarreled } \\ \text { m zuru } & \text { I stole } \\ \text { m zoro } & \text { I hid }\end{array}$

It has been stated earlier that vowel-harmony is found in Dravidian languages like Telugu. So it is a quite natural for Kui to have vowel-harmony as it is a Dravidian language and it also has close affinities with Telugu. Kui has only six vowels they are / i, e, a, o u / which can be arranged in a chat as follows:

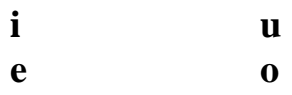

$\mathbf{a}$

In this language the vowels in two successive syllables may be the same or different from another. The study of vowel-harmony is confined only to the two successive syllables may be the same or different from another. The study of vowel-harmony is confined only to the word level in this paper because the data are controlled and vowel-harmony could be found in a few words only. That is when a singular noun is made plural by adding a plural suffix to the singular stem.

The following table shows the change that takes place in singular and plural forms.

\begin{tabular}{|l|l|l|}
\hline Column-I (singular) & Gloss & Column-II (singular) \\
\hline pasuri & shawl & pasuraka \\
\hline sabali & goldsmith instrument & sabalaka \\
\hline barsai & hoe & barasaka \\
\hline mu:tali & hammer & mu:talaka \\
\hline diuri & chisel & di? uraka \\
\hline nã:geli & plough & nã:gelaka \\
\hline guguri & pigeon & guguraka \\
\hline Sa:nd'si & a pair of pincers & sa:nd?'saka \\
\hline
\end{tabular}

Table-1: In the column I the singular nouns have /i/ as the final vowel which has been transformed into /a/ in the column II that contains the plural forms. This happens when the plural marker /-ka/ is added to the singular stem ending in /i/. Because /i/ of the stem gets totally assimilated to /a/ of the above plural marker/-ka/. Let us take an example:

$$
\text { Pasuri+ka } \rightarrow \text { pasuraka }
$$

Here the stem the final vowel /i/ is being affected by the /a/ of the plural suffix /-ka/. Let us compare the forms for /pasuri/ "shawl" and /pasuraka/ "shawls" respectively. /pasuraka/ evidently consists of the morpheme /pasuri/ 'shawl' followed by the plural suffix /-ka/. Though the expected form is /pasurika/ actually we get /pasuraka/. 
The occurrence of /pasuraka/ instead of /pasurika/ is not at all surprising if we examine the rest of the data. The same kind of change is also found in all other cases. The underlying vowel /i/ of /pasuri/ changing to /a/ under the influence of the [a] of the /-ka/ suffix.

Now we see why /i/ of the singular nouns of column I of table I I have been transformed to /a/ in the plural forms of Column-II. In terms of distinctive features /i/ is $\left[\begin{array}{c}- \text { back } \\ - \text { round } \\ + \text { high }\end{array}\right]$ and /a/ $\left[\begin{array}{c}+ \text { back } \\ - \text { round } \\ + \text { low }\end{array}\right]$.

So there is an assimilation of features, i.e., backness and height. In other words, [-back] become $[+$ back $]$ and $[+$ high $]$ becomes $[+$ low $]$.

\section{Conclusion}

To conclude let us briefly state the findings of the present study.

(i) Vowel-harmony is noticed in Kui only when the singular items end in /i/ and the plural suffix that follows them is /-ka/.

(ii) Under the influence of /a/ of the plural suffix /-ka/ the stem final vowel /i/ is transformed into /a/. Here $\left[\begin{array}{c}+ \text { High } \\ + \text { back }\end{array}\right]$ features of /i/ are assimilated to the $\left[\begin{array}{c}+ \text { Low } \\ + \text { back }\end{array}\right]$ features of /a/.

\section{Limitation of the study}

The study is based on limited data collected. Hence these findings are not the ultimatum; many more findings may be possible if further research is done in such areas of study

\section{Reference}

Dash, G.B. 1981. Structure of Kui language, Santinikatan: Viswa-Bharati University (unpublished, Ph.D. dissertation).

Census of India, 2001

Fudge, Erik, C (1973): Phonology (Penguin Books)

Gleason, H. A. Jr. (1968): An introduction to Descriptive Linguistics.

Grierson, G.A. (1906): Linguistics survey of India, Vol. II, Calcutta

Mahapatra, Kh, 1997. 'Tribal language and culture of Orissa' in Tribal language of Orissa, Bhubaneswar: Academy of Tribal Dialect and Culture. P.1-20.

Mahaptra, B.P. 1989. Tribal language of Orissa, Bhubaneswar: Academy of Tribal Dialect and culture.

Mohanty Gopinath (1956): Kuvi Kondha Bhasa0-Tottwo

N. Ramaswami, 1999. Common linguistic features of Indian languages: Phonetics, Mysore: CIIL publication.

Patel, P.N. 1991. Kuvi, Bhubaneswar: Academy of Tribal dialects and culture.

Penthoi, G. C. 2013. A contrastive Analysis of Odia and Kui, Trupti Publication, Bhubaneswar.

Penthoi, G. C. 2015. 'Kui’ Eka Bhasha tatwika Adhyayan, In. Patanayak, D. P. (Ed). Proceeding of 2nd National Language Conference. Bhubaneswar. 
Penthoi, G. C. 2016. Vowel Phonology of 'Kui', In. Nanda, S; Biswal, A; Sinha, S. (eds). Post Colonial Reflections, Literature, Language and Culture.

Pradhan, S., 1998. Tribhasi-Kui-Vyakarana (in Odia), G. Udayagiri, Kandhamal (Orissa), Berhampur: Venketswar Power Press.

Schulze, F.V.P. 1911. A grammar of the Kui language, Madras.

Winfield, W.W. 1929. A vocabulary of the Kui language (Kui English), Asiatic society of Bengal, Calcutta. 